\title{
The impact of accessibility and service quality on the frequency of patient visits to the primary diabetes care provider: results from a cross-sectional survey performed in six European countries
}

Uwe Konerding ${ }^{1,2^{*}}$ (D), Tom Bowen ${ }^{3}$, Sylvia G. Elkhuizen ${ }^{4}$, Raquel Faubel ${ }^{5,6}$, Paul Forte ${ }^{3}$, Eleftheria Karampli ${ }^{7}$, Tomi Malmström ${ }^{8}$, Elpida Pavi ${ }^{7}$ and Paulus Torkki ${ }^{8,9}$

\begin{abstract}
Background: Visits to the primary diabetes care provider play a central role in diabetes care. Therefore, patients should attend their primary diabetes care providers whenever a visit is necessary. Parameters that might affect whether this condition is fulfilled include accessibility (in terms of travel distance and travel time to the practice), as well as aspects of service quality (for example in-practice waiting time and quality of the provider's communication with the patient). The relationships of these variables with the frequency of visits to the primary diabetes care provider are investigated.

Methods: The investigation is performed with questionnaire data of 1086 type 2 diabetes patients from study regions in England (213), Finland (135), Germany (218), Greece (153), the Netherlands (296) and Spain (71). Data were collected between October 2011 and March 2012. Data were analysed using log-linear Poisson regression models with self-reported numbers of visits in a year to the primary diabetes care provider as the criterion variable. Predictor variables of the core model were: country; gender; age; education; stage of diabetes; heart problems; previous stroke; problems with lower extremities; problems with sight; kidney problems; travel distance and travel time; in-practice waiting time; and quality of communication. To test region-specific characteristics, the interaction between the latter four predictor variables and study region was also investigated.
\end{abstract}

\footnotetext{
* Correspondence: uwe.konerding@uni-bamberg.de

'Trimberg Research Academy, University of Bamberg, 96045 Bamberg, Germany

${ }^{2}$ Department of Psychology and Psychotherapy, Witten/Herdecke University, Alfred-Herrhausen-Straße 50, 58448 Witten, Germany

Full list of author information is available at the end of the article
}

(C) The Author(s). 2020 Open Access This article is licensed under a Creative Commons Attribution 4.0 International License, which permits use, sharing, adaptation, distribution and reproduction in any medium or format, as long as you give appropriate credit to the original author(s) and the source, provide a link to the Creative Commons licence, and indicate if changes were made. The images or other third party material in this article are included in the article's Creative Commons licence, unless indicated otherwise in a credit line to the material. If material is not included in the article's Creative Commons licence and your intended use is not permitted by statutory regulation or exceeds the permitted use, you will need to obtain permission directly from the copyright holder. To view a copy of this licence, visit http://creativecommons.org/licenses/by/4.0/. The Creative Commons Public Domain Dedication waiver (http://creativecommons.org/publicdomain/zero/1.0/) applies to the data made available in this article, unless otherwise stated in a credit line to the data. 
(Continued from previous page)

Results: When study regions are merged, travel distance and in-practice waiting time have a negative effect, travel time no effect and quality of communication a positive effect on visit frequency (with the latter effect being by far largest). When region specific effects are considered, there are strong interaction effects shown for travel distance, in-practice waiting time and quality of communication. For travel distance, as well as for in-practice waiting time, there are region-specific effects in opposite directions. For quality of communication, there are only differences in the strength with which visit frequency increases with this variable.

Conclusions: The impact of quality of communication on visit frequency is the largest and is stable across all study regions. Hence, increasing quality of communication seems to be the best approach for increasing visit frequency.

Keywords: Travel distance, Travel time, In-practice waiting time, Provider-patient communication, Health care provider, Visit, Accessibility to care, Type 2 diabetes

\section{Background}

Global diabetes prevalence in 2019 is estimated to be 9.3\% (463 million people), rising to $10.2 \%$ (578 million) by 2030 and $10.9 \%$ (700 million) by 2045 [1] and, hence, diabetes care constitutes an important part of health care provision. Although diabetes can lead to a wide range of medical complications involving a range of different care professionals there is usually only one lead clinician that coordinates and provides the majority of this care. In the following text, this person is referred to as the primary diabetes care provider. In most cases, this primary diabetes care provider is a general practitioner or, in some countries, a specialist diabetes nurse. The primary diabetes care provider diagnoses the patient's medical condition; discusses the treatment with the patient; provides drugs and any necessary medical equipment required for the treatment; counsels the patient; and supervises the patient's adherence to the treatment regime. However, this can only be done if patients visit their primary care provider sufficiently frequently and diabetes care needs to be designed and organised to facilitate this. This, in turn, requires knowledge about the determinants of patient visits to the primary diabetes care provider.

Certainly, the most important determinant of visits to the primary diabetes care provider is cost: whether the patients must pay for the visit out of their own pocket; whether any costs are reimbursed through a health insurance scheme; or whether the system is financed through general taxation. There might, however, be other factors that affect the frequency of visits to the provider, which become more prominent once any cost issues are removed. These include the accessibility of the provider to the patient and the service quality of the provider. Important aspects of accessibility are travel distance and travel time from patient residence to provider location. Important aspects of the provider's service quality, i.e. the extent to which the provider tries to respect the patients' needs in all regards related to their interaction, are waiting time in the providers' practice to see the clinician (i.e. the in-practice waiting time) and the quality of the provider's communication with the patient. Long travel distances, long travel times, long inpractice waiting times (or combinations of these of these circumstances) might negatively affect the number of visits, whereas quality of communication might have a positive effect.

Several studies provide relevant evidence for the hypotheses formulated above. There are statistically significant negative associations between travel distance and visits to primary care providers [2], attendance at hospital emergency departments [3], frequency of visits to a dentist following traumatic dental injury [4], the decision to attend screening for gestational diabetes mellitus [5], the use of insulin [12] and glycaemic control [13 and 14] However, there was no statistically significant relationship with compliance for mammography [6] and healthrelated quality of life [7]. Other studies have produced statistically significant negative associations of travel time with the tendency to visit an endocrinologist [8], the likelihood of visiting a physician [9], the likelihood of attending a hospital [9], the likelihood of in-facility delivery [10], the frequency of pre-natal care visits $[10,11]$, and health-related quality of life [7]. However, there was no statistically significant association with the likelihood of visiting a general practitioner $[15,16]$, the likelihood of visiting a gynaecologist [16], compliance to mammography [6] and the delay in seeking care in case of a malaria infection [17]. Further studies have produced statistically significant associations of in-practice waiting time with frequency of physician visits [18] and healthrelated quality of life [7]. Moreover, some studies [1921] show that quality of communication with the provider is positively associated with self-care.

At present, there is no study regarding the relationship of travel distance, travel time, in-practice waiting time and quality of provider-patient communication with the frequency of visiting the primary diabetes care provider. This study redresses that gap in the research literature with regard to care for diabetes type 2 . 


\section{Methods}

\section{Study regions, study participants and study conduction}

The investigation is based on the same data set that was used by Konerding et al. [7] to investigate the impact of travel distance, travel time and in-practice waiting time on health-related quality of life. These data were originally collected in the European FP-7 project 'MANAGED OUTCOMES' [22, 23], which was concerned with analysing health care provider networks in England, Finland, Germany, Greece, the Netherlands and Spain. In all of these countries, the majority of medical services are either reimbursed by health insurances or financed through taxation. However, there are differences between each country as to how the access to health care is regulated. In terms of the classification system of Reibling [24], England, the Netherlands and Spain are strong gatekeeping and low supply states, i.e. these states strongly regulate access to health care providers by having clinical expert 'gatekeepers' (general practitioners) decide which service should be provided to the patient. In turn, this means that these states - in theory at least - can have a lower supply of health care. Germany and Greece, by contrast, are weakly regulated and high supply states in the terminology of Reibling, i.e. these states have minimal gatekeeper control, which means that they have to provide a high supply of health care. Finally, in Reibling's terminology, Finland is a 'mixed regulation state', i.e. this state regulates access to health service partially by gatekeeping and partially by cost sharing and has a moderate supply of health care [23].

In the MANAGED OUTCOMES project, health provider networks for different health conditions were investigated, including networks for providing type 2 diabetes care. For each country, one local network was selected and data were collected from the diabetes service locations in these networks. In England these locations were seven general practitioner practices associated with the Tower Hamlets Primary Care Trust in the east London Borough of Tower Hamlets. In Finland, these were the health centres of eight municipalities within Keski-Suomi (Central Finland). In Germany, these were one general practitioner and one diabetologist in the city of Bamberg, and two general practitioners and one diabetologist in the surrounding rural district of Bamberg. In Greece, these were five different institutions providing outpatient care for diabetes in the regional unit of Heraklion on the island of Crete. In the Netherlands, these were five general practitioner health centres in the region Nieuwe Waterweg Noord en Delft Westland Oostland. In Spain, this was one primary health area in the region of Valencia [7]. The main criterion for selecting the locations and health care providers was their willingness to cooperate in the study.

Part of the investigation comprised surveys of type 2 diabetes patients, which were undertaken with the assistance of the investigated primary diabetes care providers. These providers selected the patients to be approached for participation according to criteria defined by the researchers. Inclusion criteria for participants were (1) that they were being treated for type 2 diabetes by the health providers investigated in the project and (2) that they were at least 18 years old. Depending on the most feasible method for each provider, patients were contacted either by post or directly when they visited their primary diabetes care provider. Patients who participated in the survey completed their questionnaires on their own without any intervention by personnel from the service provider or the research team. Depending on the most feasible method for the particular provider, participants then returned their completed questionnaires either by post directly to the local project study centres, or to the care provider who then passed them on to the study centres. With the exception of Greece, all surveys were approved by national ethics committees. In Greece, the approval was granted by the relevant committee of the hospital. Data were collected between October 2011 and March 2012 [7].

\section{Questionnaire variables}

The patient questionnaire applied in the survey contained questions addressing different topics. Two items addressed the mastery of the questionnaire language. Demographic data items included: sex, age and educational level of the patient (those leaving school directly after the minimum school leaving age of the country were classified as 'low level'; those who had stayed in education beyond that were classified as 'high level'). Health data items included the stage of diabetes, which was characterised by the three levels of treatment: (1) diet only (2) oral anti-diabetic agents but no insulin, and (3) insulin. The patients were also asked about any of five secondary complications they might have had arising from the diabetes: heart problems; previous stroke; problems with lower extremities; problems with sight; and kidney problems (either having had a kidney transplant or being dependent on dialysis). Other data referred to the diabetes service they attended: travel time; travel distance; in-practice waiting time; quality of communication; and the number of visits to the primary diabetes care provider within the last year (see Table 1).

The questions addressing mastery of the questionnaire language were included in order to determine the sample of participants included in the analyses, while all of the other variables were considered in the analyses themselves. In the following sections, these will be referred to as the 'investigated variables'. According to their status in the statistical analyses, the investigated variables were subdivided into three categories. The number of provider visits, i.e. visit frequency, was 
classified as the criterion variable; travel time, travel distance, in-practice waiting time and quality of communication were classified as 'focal predictor' variables, and all remaining investigated variables were applied as control variables.

\section{Inclusion criteria}

Patients were only included in the analysis if they had indicated that they mastered the questionnaire language well, and if they had given information about travel time; travel distance; in-practice waiting time, quality of communication; and the number of provider visits they had in the last year. Patients were excluded from analyses if data for more than two control variables were missing. The strict criteria with regard to missing data were chosen, because the number of missing data was assumed to reflect the thoroughness with which the respondent has answered the questionnaire. Accordingly, data of patients with more than two missing data were assumed to be less reliable and less valid than data of the other patients and it therefore seemed wise to exclude them from the analyses.

Patients were included independently of the number of visits to their primary diabetes care provider in the year preceding the survey, i.e. patients who had not visited at all during this time were also included. This was necessary because the relationship of the focal predictor variables with the number of visits was investigated and because 'zero visits' constituted a possible outcome. It could be argued that the answers given by patients with zero visits in the last year are less valid than the answers of regular visitors. However, even if they are less valid in the sense that they do not adequately describe the reality they can validly reflect what the patients think about the reality and it is this thinking which determines the behaviour [25].

\section{Statistical analyses}

For the inclusion criteria, descriptive statistics were computed based on the total number of questionnaires distributed and, for the investigated variables, based on the questionnaires which met the inclusion criteria. Percentages were computed for dichotomous variables, and means, standard deviations, minima and maxima for continuous variables. This was undertaken for both the total sample and separately for the six region-specific samples. Regional differences regarding dichotomous variables were statistically tested using chi-square tests, and regional differences regarding continuous variables using Kruskal-Wallis tests.

The relationship of travel distance, travel time, inpractice waiting time and quality of communication with visits to the primary diabetes care provider was investigated using log-linear Poisson regression models [26] with frequency of visits as the criterion. Poisson regression models are specially designed for predicting count variables as for example the frequency of visits. The de-logarithmised coefficients estimated by these models reflect the proportion with which the predicted variable increases or, respectively, decreases when the corresponding predictor variable increases by one unit.

All focal predictor variables and all control variables were applied as predictor variables. All focal predictors were entered together into the same model as they were considered to reflect different aspects. This also applies to travel distance and travel time because travel time is not solely determined by travel distance, but also by factors such as the method of transport available to the patient and road congestion. Hence, both variables might have an independent effect on the visits to the diabetes care provider. Dummy-coded study regions were included to control for region-specific tendencies regarding provider visits. The status of diabetes and the five secondary complications of diabetes were included to control for the effect of health status because health status usually affects the number of health care provider visits $[2-4,8,9,15]$. The three socio-demographic variables (age, gender and education) were included because these variables are known to be related to health status [27-30] and thus might help to control for those aspects of health status that are not reflected by diabetes status and secondary complications. Taken together, the demographic variables and the variables directly addressing health status can be regarded as variables covering the need for visits to the primary diabetes care provider.

The coefficients for all predictor variables were estimated and tested for deviation from zero. Fit of the models was investigated by comparing the complete model via a likelihood ratio test with only the criterion mean as predictor and by using the index proposed by Cameron and Windmeijer [31] (CW-index). ${ }^{1}$ The CWindex serves a similar purpose as the multiple $\mathrm{R}$ square in multivariate linear regression. This index is 0 when the model predicts the criterion as poorly as the criterion mean, and it is 1 when the model predicts the criterion optimally. The extent to which a specific predictor variable contributes to predicting visit frequency was assessed by subtracting the CW-index for a model without this variable from the CW-index for the complete model. To obtain a statistic that can be interpreted analogously to the percentage of variance exclusively explained by a specific predictor variable in a multivariate regression model, the resulting difference was multiplied

\footnotetext{
${ }^{1}$ Following a convention reported by Greene [26] $\ln (0)$ was set equal to zero when $\mathrm{CW}$-indices were computed.
} 
Table 1 Questions in the questionnaire applied for the investigation

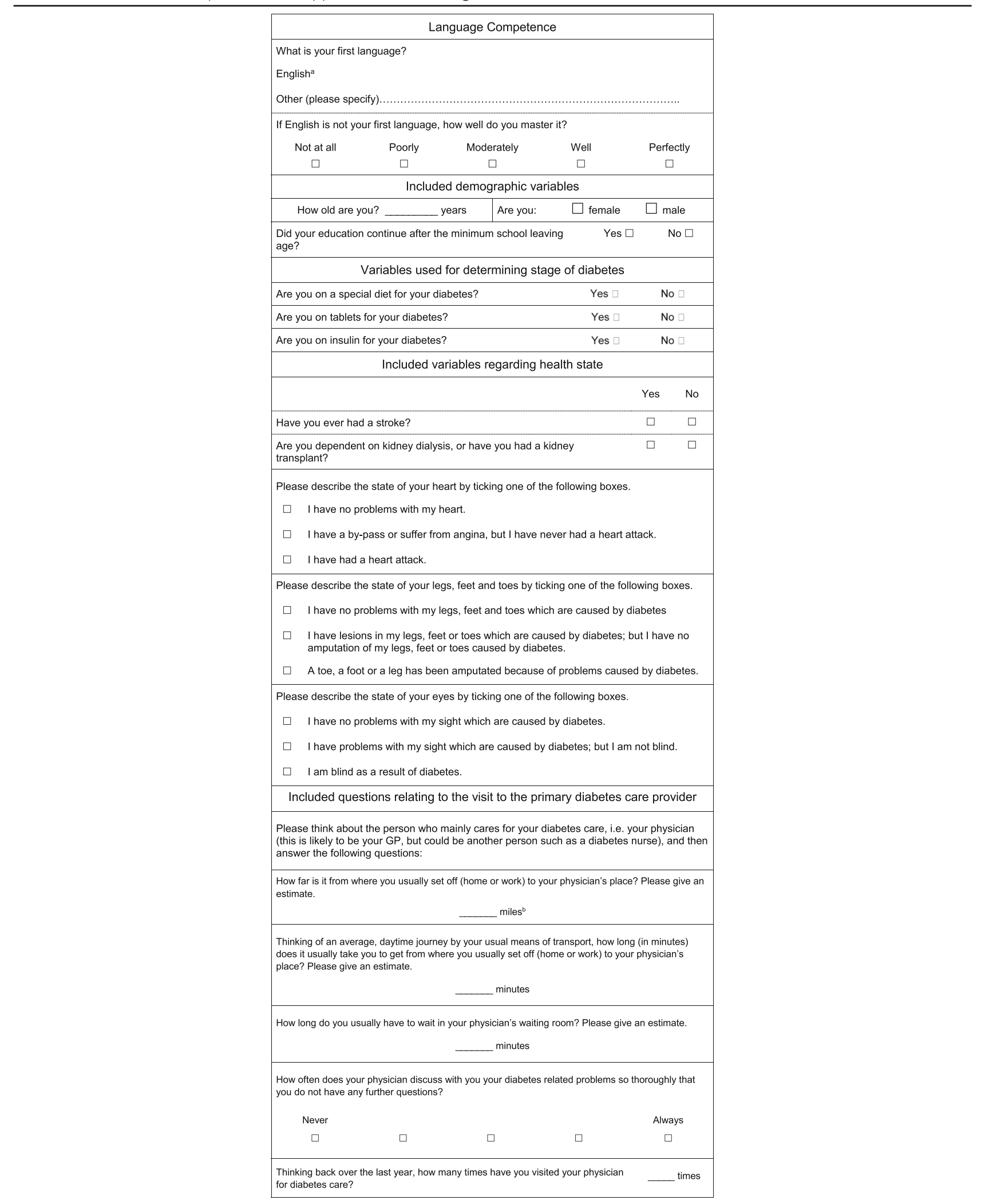

${ }^{\mathrm{a} F o r}$ all other countries than England the respective national language was inserted

${ }^{\mathrm{b}}$ For all other countries than England kilometres were asked. For the statistical analyses, the English miles were transformed into kilometres 
by 100 . In contrast to the coefficient belonging to a predictor variable, the statistic just described is independent of the unit with which the predictor variable is measured. Therefore, by means of this statistic, the contributions of different predictor variables can be compared.

The correlations between the focal predictors were computed and, to investigate the influence of these correlations on the results, four additional models were computed in each of which a different focal predictor was omitted.

To investigate the stability of the results across the six study regions, the interactions between the focal predictor variables and the study regions were analysed. The statistical significance for the interactions with a specific focal predictor was tested via a likelihood ratio test by comparing a model containing all predictor variables and all investigated interactions with a model from which the interaction terms for the respective focal predictor variable had been removed. In addition, the contribution of the interaction for explaining the visit frequency was investigated using $\mathrm{CW}$-indices in an analogous manner as described above for the main effects. To investigate the extent to which possible interactions can be attributed to the countries' health care systems, analogue computations were performed after grouping the study regions according to the Reibling categories assigned to the corresponding country [23, 24] (see above).

To check the generalisability of the results, all analyses were performed in two variants: 1) for all included participants (i.e. persons who had up to two missing data items for the control variables), and 2) for participants with complete data for all investigated variables. For the analysis referring to participants with missing values, the missing values were imputed by the study regionspecific means. As data possessing less than interval scale level were dummy coded, the study regionspecific relative frequencies of persons belonging to the respective category were taken for imputing missing values of these data.

\section{Results}

Altogether 6245 questionnaires were distributed of which 1638 (26.2\%) were returned and 1086 (17.4\%) met the inclusion criteria (see Table 2). The proportions of included questionnaires vary from $6.4 \%$ for England to $47.2 \%$ for Germany (see Table 2). The proportion of included questionnaires is smallest in England because about $40 \%$ of all respondents in this sample were of Bangladeshi ethnicity who, due to lower levels of stated proficiency in the English language, did not meet the inclusion criteria. In total 829 (13.3\%) of the included questionnaires had no missing data for the investigated variables (see Table 2). There are study region differences with regard to all investigated variables except for gender, and for kidney problems (see Table 3). In the sample of all included patients, the numbers of visits per year range from zero to 40 with a mean of 3.9 and a standard deviation of 3.1 (see Table 3).

The results of the Poisson regressions for predicting yearly provider visits are largely the same when patients with up to two missing values and when only patients with complete data are included (See Table 4). In both cases, the model predicts visit frequency essentially better than the mean (in both cases: $p<0.001$ ). When patients with missing data are considered, the CW-Index is 0.19 . When only patients with complete data are considered, it is 0.18 . The control variables contribute largely to the model prediction (See Table 4). There are statistically significant negative relationships of travel distance and in-practice waiting time with visit frequency. For travel distance, this relationship is large; for in-practice waiting time it is small. The relationship between travel time and visit frequency is not statistically significant. Quality of communication has a very strong statistically

Table 2 General information about the sample

\begin{tabular}{|c|c|c|c|c|c|c|c|}
\hline & English region & Finnish region & German region & Greek region & Dutch region & Spanish region & Total sample \\
\hline \multicolumn{8}{|c|}{ Statistics determining the study sample ${ }^{a}$} \\
\hline Questionnaires distributed & 3343 & 436 & 462 & 600 & 779 & 625 & 6245 \\
\hline Questionnaires returned & 475 (14.2\%) & $183(42.0 \%)$ & $286(61.9 \%)$ & $179(29.8 \%)$ & $400(51.3 \%)$ & $115(18.4 \%)$ & $1638(26.2 \%)$ \\
\hline Sufficient language competence ${ }^{b}$ & $313(9.4 \%)$ & $183(42.0 \%)$ & $282(61.0 \%)$ & $179(29.8 \%)$ & $387(49.7 \%)$ & $115(18.4 \%)$ & $1459(23.4 \%)$ \\
\hline Sufficient data ${ }^{c}$ & $286(8.6 \%)$ & $135(31.0 \%)$ & $221(47.8 \%)$ & $153(25.5 \%)$ & $304(39.0 \%)$ & $71(11.4 \%)$ & $1170(18.7 \%)$ \\
\hline Participants included & $213(6.4 \%)$ & $135(31.0 \%)$ & $218(47.2 \%)$ & $153(25.5 \%)$ & $296(38.0 \%)$ & $71(11.4 \%)$ & $1086(17.4 \%)$ \\
\hline Complete data $^{\mathrm{d}}$ & $160(4.8 \%)$ & $103(23.6 \%)$ & $172(37.2 \%)$ & $110(18.3 \%)$ & $227(29.1 \%)$ & 57 (9.1\%) & 829 (13.3\%) \\
\hline
\end{tabular}

a Percentages refer to questionnaires distributed

${ }^{\mathrm{b}}$ The English sample contained a large proportion of persons with Bangladeshi ethnicity who had lower levels of stated proficiency in the English language

c Participants with complete data for the criterion variable and the four focal predictor variables and with at most two missing values for the control variables

${ }^{\mathrm{d}}$ Participants with complete data for all investigated variables 
Table 3 Distributions of the investigated variables

\begin{tabular}{|c|c|c|c|c|c|c|c|c|}
\hline & English region & Finnish region & German region & Greek region & Dutch region & Spanish region & Total sample & Region differences \\
\hline \multicolumn{9}{|l|}{ Control variables $^{D}$} \\
\hline \multicolumn{9}{|l|}{ Gender } \\
\hline Valid data & 209 & 132 & 217 & 153 & 290 & 70 & 1071 & \\
\hline Male & $64.6 \%$ & $65.2 \%$ & $53.9 \%$ & $58.2 \%$ & $59.3 \%$ & $55.7 \%$ & $59.6 \%$ & n.s. ${ }^{c}$ \\
\hline \multicolumn{9}{|l|}{ Age in years } \\
\hline Valid data & 211 & 133 & 218 & 153 & 294 & 71 & 1080 & \\
\hline Mean (SD) & $63.0(11.9)$ & $63.5(9.6)$ & $65.7(11.2)$ & $66.0(10.6)$ & $65.0(10.0)$ & $69.3(11.4)$ & $65.0(10.9)$ & $p<0.001^{d}$ \\
\hline \multicolumn{9}{|l|}{ Education } \\
\hline Valid data & 191 & 129 & 211 & 150 & 287 & 68 & 1036 & \\
\hline High & $39.8 \%$ & $59.7 \%$ & $66.4 \%$ & $27.3 \%$ & $76.3 \%$ & $26.5 \%$ & $55.1 \%$ & $p<0.001^{c}$ \\
\hline \multicolumn{9}{|l|}{ Stage of diabetes } \\
\hline Valid data & 204 & 124 & 207 & 125 & 276 & 63 & 999 & \\
\hline Diet only & $13.7 \%$ & $3.2 \%$ & $7.7 \%$ & $1.6 \%$ & $19.9 \%$ & $4.8 \%$ & $10.8 \%$ & $p<0.001^{c}$ \\
\hline Oral, no insulin & $65.7 \%$ & $69.4 \%$ & $58.9 \%$ & $68.8 \%$ & $65.9 \%$ & $63.5 \%$ & $65.1 \%$ & \\
\hline Insulin & $20.6 \%$ & $27.4 \%$ & $33.3 \%$ & $29.6 \%$ & $14.1 \%$ & $31.7 \%$ & $24.1 \%$ & \\
\hline \multicolumn{9}{|l|}{ Heart problems } \\
\hline Valid data & 207 & 126 & 193 & 144 & 284 & 70 & 1024 & \\
\hline Yes & $25.1 \%$ & $19.0 \%$ & $21.8 \%$ & $30.6 \%$ & $14.8 \%$ & $18.6 \%$ & $21.2 \%$ & $p<0.01^{c}$ \\
\hline \multicolumn{9}{|l|}{ Previous stroke } \\
\hline Valid data & 212 & 135 & 217 & 151 & 289 & 70 & 1074 & \\
\hline Yes & $7.5 \%$ & $2.2 \%$ & $10.6 \%$ & $6.0 \%$ & $4.5 \%$ & $5.7 \%$ & $6.3 \%$ & $p<0.05^{c}$ \\
\hline \multicolumn{9}{|c|}{ Problems with lower extremities } \\
\hline Valid data & 206 & 134 & 215 & 148 & 283 & 71 & 1057 & \\
\hline Yes & $17.0 \%$ & $12.7 \%$ & $26.0 \%$ & $12.2 \%$ & $5.3 \%$ & $15.5 \%$ & $14.4 \%$ & $p<0.001^{c}$ \\
\hline \multicolumn{9}{|c|}{ Problems with sight } \\
\hline Valid data & 210 & 133 & 216 & 151 & 292 & 70 & 1072 & \\
\hline Yes & $24.3 \%$ & $10.5 \%$ & $17.6 \%$ & $15.9 \%$ & $8.6 \%$ & $28.6 \%$ & $16.0 \%$ & $p<0.001^{c}$ \\
\hline \multicolumn{9}{|c|}{ Problems with kidney } \\
\hline Valid data & 207 & 133 & 212 & 145 & 286 & 71 & 1054 & \\
\hline Yes & $0.5 \%$ & $0.0 \%$ & $0.9 \%$ & $0.7 \%$ & $0.0 \%$ & $0.0 \%$ & $0.4 \%$ & n.s. ${ }^{c}$ \\
\hline \multicolumn{9}{|l|}{ Focal predictors ${ }^{\mathrm{e}}$} \\
\hline \multicolumn{9}{|c|}{ Travel distance to provider in kilometres } \\
\hline Mean (SD) & $1.6(2.9)$ & $9.2(10.7)$ & $5.7(6.1)$ & $15.8(20.6)$ & $1.9(1.8)$ & $1.5(1.3)$ & $5.4(10.4)$ & $p<0.001^{d}$ \\
\hline \multicolumn{9}{|c|}{ Travel time to provider in minutes } \\
\hline Mean (SD) & $14.6(9.9)$ & $16.7(11.5)$ & $13.1(9.2)$ & $28.8(25.9)$ & $7.7(5.1)$ & $14.4(9.8)$ & $14.7(14.2)$ & $p<0.001^{d}$ \\
\hline \multicolumn{9}{|c|}{ In-practice waiting time in minutes } \\
\hline Mean (SD) & $18.5(13.9)$ & $13.7(10.3)$ & $43.6(32.5)$ & $52.8(41.1)$ & $12.9(19.6)$ & $38.2(30.0)$ & $27.5(30.1)$ & $p<0.001^{d}$ \\
\hline \multicolumn{9}{|c|}{ Quality of communication ${ }^{f}$} \\
\hline Mean (SD) & $3.9(1.2)$ & $4.2(1.0)$ & $4.2(1.1)$ & $3.9(1.3)$ & $4.4(1.0)$ & $3.5(1.5)$ & $4.1(1.2)$ & $p<0.001^{d}$ \\
\hline \multicolumn{9}{|l|}{ Criterion variable $\mathrm{e}^{\mathrm{e}}$} \\
\hline \multicolumn{9}{|c|}{ Numbers of physician visits per year } \\
\hline Mean (SD) & $3.3(3.0)$ & $2.5(1.4)$ & $4.6(4.0)$ & $4.9(4.3)$ & $3.7(1.3)$ & $4.6(5.9)$ & $3.9(3.3)$ & $p<0.001^{d}$ \\
\hline
\end{tabular}

a.s. not significant

b Valid data vary due to missing values

c Pearson's chi-square test

Kruskal-Wallis test ${ }^{\mathrm{e}}$

e Valid data are identical with the numbers of participants included (see Table 1)

${ }^{\mathrm{f}}$ Coded from 1 for worst quality to 5 for best quality 
Table 4 Prediction of yearly patient visits to the primary diabetes care provider

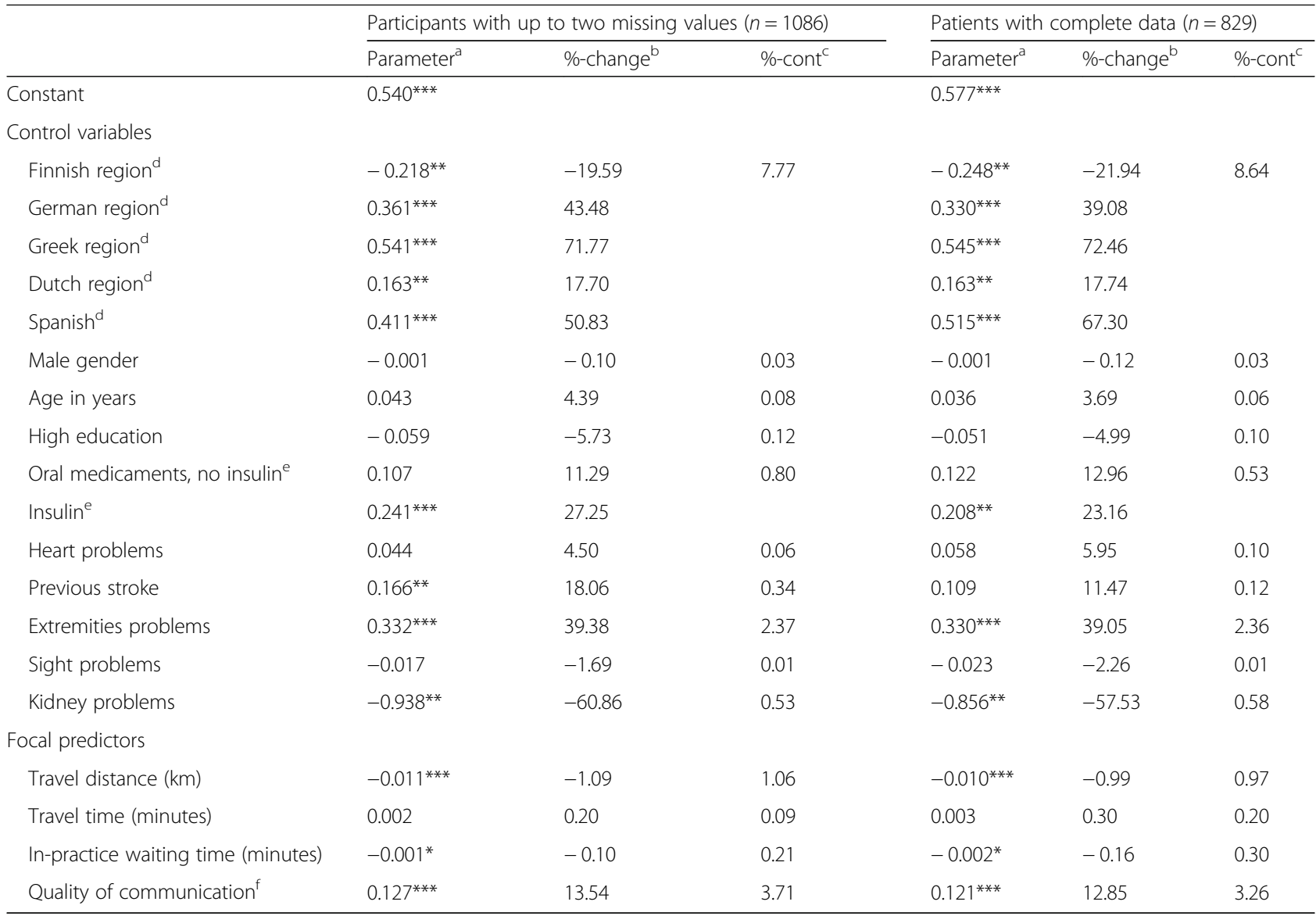

${ }^{a}$ Asterisks behind the values symbolize statistical significances for deviation from zero with ${ }^{*}=p<0.05,{ }^{* *}=p<0.01$, and ${ }^{* * *}=p<0.001$

b Percentage of increase or, respectively, decrease of yearly visits when the respective predictor variable increases for one unit

' Contribution of the respective predictor variable to the prediction of the complete model (one hundred times the difference between the CW-Indices for the complete model and the models without the respective predictor variable)

${ }^{\mathrm{d}}$ The reference category is England

${ }^{\mathrm{e}}$ The reference category is treatment only by diet

${ }^{f}$ Coded from 1 for worst quality to 5 for best quality

significant positive relationship with visit frequency (See Table 4).

The correlations between the four focal predictors are largely the same for patients with up to two missing values and for patients with complete data. Quality of communication does not correlate with travel distance and travel time. In the remaining cases, the correlations deviate from zero on the 0.001 level. For travel distance and travel time, the correlations are 0.696 for patients with up to two missing values and 0.698 for patients with complete data. For travel distance and in-practice waiting time, these values are 0.215 and 0.254 . For travel time and in-practice waiting time, they are 0.273 and 0.286 . For in-practice waiting time and quality of communication, they are -0.132 and -0.150 . When travel time or in-practice waiting time are removed from the model, the pattern for the coefficients of the remaining three focal predictors stays unaltered both for patients with up to two missing values and for patients with complete data. When travel distance is removed, the coefficient pattern for the remaining three variables stays largely the same for patients with complete data, but for patients with up to two missing values a slightly negative statistically significant effect of travel time comes into existence. When quality of communication is removed, the results are largely the same for patients with up to two missing data and for patients with complete data. In both cases, the results for travel distance and inpractice waiting time stay largely unaltered, but a slightly positive statistically significant effect of travel time arises, i.e. the visit frequency increases with increasing travel time.

When terms for the interaction between study regions and focal predictors are added, the model predicts visit frequency essentially better than the mean (for patients with up to two missing values and for patients with 
Table 5 Prediction of yearly patient visits to the primary diabetes care provider; country specific coefficients for focal predictors ${ }^{a}$

\begin{tabular}{|c|c|c|c|c|c|c|c|}
\hline & English region & Finnish region & German region & Greek region & Dutch region & Spanish region & $\begin{array}{l}\text { Country } \\
\text { differences }^{\mathrm{b}}\end{array}$ \\
\hline \multicolumn{8}{|c|}{ Participants with up to two missing values $(n=1086)$} \\
\hline Travel distance in kilometres & $0.027^{* *}$ & 0.005 & -0.009 & $-0.015^{* * *}$ & -0.005 & $-0.110^{*}$ & $1.02^{* * *}$ \\
\hline Travel time in minutes & 0.004 & 0.000 & -0.002 & $0.005^{*}$ & -0.003 & $0.012^{*}$ & 0.24 \\
\hline In-practice waiting time in minutes & -0.002 & $-0.014^{*}$ & 0.001 & $-0.006^{* * *}$ & -0.001 & $0.006^{* * *}$ & $2.16^{* * *}$ \\
\hline Quality of communication ${ }^{c}$ & $0.163^{* * *}$ & $0.133^{*}$ & $0.142^{* * *}$ & 0.030 & $0.068^{*}$ & $0.315^{* * *}$ & $1.56^{* * *}$ \\
\hline \multicolumn{8}{|l|}{ Patients with complete data $(n=829)$} \\
\hline Travel distance in kilometres & $0.025^{*}$ & 0.006 & -0.003 & $-0.014^{* * *}$ & 0.002 & -0.112 & $1.15^{* *}$ \\
\hline Travel time in minutes & 0.004 & 0.001 & 0.001 & $0.006^{* *}$ & -0.004 & $0.015^{*}$ & 0.32 \\
\hline In-practice waiting time in minutes & $-0.009^{*}$ & $-0.020^{*}$ & 0.002 & $-0.009^{* * *}$ & -0.007 & $0.006^{* * *}$ & $4.04^{* * *}$ \\
\hline Quality of communication ${ }^{c}$ & $0.127^{* *}$ & $0.190^{*}$ & $0.159^{* * *}$ & 0.004 & 0.068 & $0.228^{* * *}$ & $1.12^{* *}$ \\
\hline
\end{tabular}

a Parameters of Poisson regression when the respective country is taken as reference for the interactions. Statistical significances for deviation from zero are symbolised with ${ }^{*}=p<0.05,{ }^{* *}=p<0.01$, and ${ }^{* * *}=p<0.001$

${ }^{\mathrm{b}}$ Contribution of the respective interactions to the prediction of the model with interactions for all four focal predictors, i.e. one hundred times the difference between the CW-Indices for the model with interactions for all focal predictors and the models without interactions for the respective focal predictor. The statistical test was performed using a likelihood ratio test between both models. Statistical significances are symbolised with ${ }^{*}=p<0.05,{ }^{* *}=p<0.01$, and ${ }^{* * *}=p<0.001$

${ }^{c}$ Coded from 1 for worst quality to 5 for best quality

complete data: $p<0.001)$. The $\mathrm{CW}$-indices increase essentially, from 0.18 to 0.24 for patients with up to two missing values and from 0.19 to 0.25 for patients with complete data. The patterns of coefficients and the corresponding statistical significances are largely the same for both groups of patients. The interaction of study regions with travel time is not statistically significant; the interactions with the remaining three focal predictors, however, are highly significant (see Table 5). For travel distance and in-practice waiting time there are even statistically significant effects in opposite directions. To be specific, in both patient groups, visit frequency increases significantly with travel distance in the English region, whereas the opposite is true in the Greek region. In a similar way, visit frequency increases significantly with in-practice waiting time in the Spanish region, whereas

Table 6 Prediction of yearly patient visits to the primary diabetes care provider; Reibling category specific coefficients for focal predictors $^{\mathrm{a}}$

\begin{tabular}{|c|c|c|c|c|}
\hline & $\begin{array}{l}\text { Strong gatekeeping, low supply } \\
\text { (England, the Netherlands, Spain) }\end{array}$ & $\begin{array}{l}\text { Mixed regulation } \\
\text { (Finland) }\end{array}$ & $\begin{array}{l}\text { Weakly regulated, high supply } \\
\text { (Germany, Greece) }\end{array}$ & $\begin{array}{l}\text { Differences between } \\
\text { categories }^{\text {b }}\end{array}$ \\
\hline \multicolumn{5}{|c|}{ Participants with up to two missing values $(n=1086)$} \\
\hline Sample sizes & 580 & 135 & 371 & \\
\hline Travel distance in kilometres & 0.011 & 0.005 & $-0.014^{* * *}$ & $0.54^{* *}$ \\
\hline Travel time in minutes & 0.002 & 0.000 & 0.003 & 0.01 \\
\hline In-practice waiting time in minutes & 0.001 & $-0.015^{*}$ & $-0.002^{* *}$ & $0.55^{* *}$ \\
\hline Quality of communication ${ }^{c}$ & $0.161^{* * *}$ & $0.132^{*}$ & $0.085^{* * *}$ & $0.29^{*}$ \\
\hline \multicolumn{5}{|l|}{ Patients with complete data $(n=829)$} \\
\hline Sample sizes & 444 & 103 & 282 & \\
\hline Travel distance in kilometres & 0.008 & 0.006 & $-0.014^{* * *}$ & $0.59^{* *}$ \\
\hline Travel time in minutes & 0.002 & 0.000 & $0.004^{*}$ & 0.03 \\
\hline In-practice waiting time in minutes & 0.001 & $-0.020^{*}$ & $-0.002^{* *}$ & $0.67^{* *}$ \\
\hline Quality of communication ${ }^{c}$ & $0.137^{* * *}$ & $0.187^{*}$ & $0.092^{* * *}$ & 0.15 \\
\hline
\end{tabular}

${ }^{a}$ Parameters of Poisson regression when the respective category is taken as reference for the interactions. Statistical significances for deviation from zero are symbolised with ${ }^{*}=p<0.05,{ }^{* *}=p<0.01$, and ${ }^{* *}=p<0.001$

${ }^{b}$ Contribution of the respective interactions to the prediction of the model with interactions for all four focal predictors, i.e. one hundred times the difference between the $\mathrm{CW}$-Indices for the model with interactions for all focal predictors and the models without interactions for the respective focal predictor. The statistical test was performed using a likelihood ratio test between both models. Statistical significances are symbolised with ${ }^{*}=p<0.05,{ }^{* *}=p<0.01$, and ${ }^{* * *}=p<0.001$

c Coded from 1 for worst quality to 5 for best quality 
the opposite is true for the Finnish and Greek regions. In contrast, visit frequency increases with quality of communication in all regions and, in most cases, this increase is statistically significant. The study regions only differ with regard to the extent of the increase. It is smallest for the Greek and largest for the Spanish region (see Table 5).

When the interaction terms for study regions are replaced by interaction terms with the Reibling categories, the model also predicts visit frequency better than the mean (for patients with up to two missing values and for patients with complete data: $p<0.001$ ). However, the $\mathrm{CW}$-indices are only slightly higher than the corresponding indices of the models without any interaction terms. These indices are 0.20 for both patient groups. Apart from this, the general pattern of results is similar to the pattern of results for interactions with study regions. There are statistically significant interaction effects with travel distance and in-practice waiting time in both patient groups and a statistically significant interaction effect for quality of communication for patients with up to two missing values (see Table 6). There are coefficients in opposite direction for travel distance and in-practice waiting time. However, the only coefficients that are statistically significant are negative (see Table 6). This applies to travel distance and to in-practice waiting time in both patient groups (see Table 6), i.e. in these cases visit frequency decreases with increasing travel distance and in-practice waiting time. For quality of communication, all coefficients are positive and statistically significant, i.e. visit frequency increases with quality of communication (see Table 6).

\section{Discussion}

\section{Discussion of the study methodology Generalisability}

The study regions and the institutions within the study regions were selected because of their willingness to cooperate in the research project. Hence, the study regions cannot be taken as prototypical examples of all regions in the corresponding country. For each institution, all eligible patients were approached to participate in the survey, but only a subset of them responded and some of those responders had to be excluded for reasons of insufficient mastery of the questionnaire language or insufficient provision of valid data. Hence, the samples finally included are not even representative of the populations of eligible patients within the study regions. The persons represented by these samples are cooperative and thorough, and native or well-integrated citizens.

Regarding interpretation of the results, the selection bias in the participants implies that the results should only be referred to the native and the well-integrated citizens in the study region. This is so, because the study gives no information as to what would hold for nonnative or not well-integrated citizens. As far as the selection bias is caused by willingness to cooperate and thoroughness, the situation is slightly different. Participants who have answered all questions can be considered to be more cooperative and more thorough than those who left out one or two questions. Hence, the sensitivity analyses indicate how willingness to cooperate and thoroughness might affect the results. When the results for patients with up to two missing values are largely the same as those for patients with complete data then this indicates that the effect found in the analysis might hold in the region specific population of all native or wellintegrated patients with type 2 diabetes.

The manner in which the study regions have been selected implies that the results found in the region cannot readily be generalised to the corresponding country. However, country-specific characteristics constitute one possible explanation of similarities and differences between the results from different study regions. An alternative explanation is that these similarities and differences are caused by other study region characteristics that are not representative of the corresponding countries. Comparison of the results from across the different study regions gives some information regarding the generalisability of results. Where results differ between the regions, this shows that these results depend on special features of the study regions and/or the corresponding patients. However, when the results are stable across the regions this indicates that similar results might be found in different regions. In this regard, performing a study with data from six different European provider networks with different participant samples constitutes an important strength of the study.

\section{Study design}

The study presented here is a cross-sectional study and so it is unclear as to whether the relationships found are actually causal and, if so, which variable is the cause and which the effect. To test this, a randomised controlled trial (RCT) would be necessary and such a study design is usually not feasible in this context. Therefore, health care design is dependent on empirical studies using weaker designs than RCTs (such as cross-sectional studies). To assess whether the relationships found in such studies are causal and what the direction of causality might be, further knowledge about the target of investigation must also be considered. The best that cross-sectional designs can produce are empirically well-substantiated hypotheses regarding causal relationships and the results presented here are to be understood precisely in this way. It is up to the health care designers to decide whether they consider the empirical substantiation as sufficient to base interventions on them. When these interventions are 
evaluated using RCTs, these evaluation studies constitute tests of the causality assumptions on which the interventions are based.

\section{Multiple testing}

As the effects of several different variables were tested at the same time, concerns regarding an increased probability of false positive results due to multiple testing might arise. However, as the statistical tests were performed as parts of multivariate regression models and as these models were highly statistically significant the different positive results of the significance tests cannot simply be explained by chance.

\section{Interpretation of the study results}

For the data combined across the six study regions a clear picture seems to emerge. The pattern of results is largely the same for patients with up to two missing data and for patients with complete data. Hence, the results could be generalised to all native or well-integrated patients in the study regions. The results indicate a moderate negative effect of travel distance on visits to the diabetes care provider, no effect due to travel time, a very slight effect of in-practice waiting time and a very strong effect due to quality of communication (see Table 4). The analyses where focal predictors were alternatively removed from the model corroborate the interpretation that it is travel distance and not travel time that negatively affects visit frequency for the aggregated data of the six study regions. This corresponds to previous research findings as there were more non-significant results in studies addressing the effect of travel time [6, 15-17] than in studies addressing the effect of travel distance [6]. However, once again, quality of communication has the by far largest effect. An increase of 1 on the five-categorical scale is associated with a $13.54 \%$ increase of visit frequency. Consequently, an increase from the lowest to the highest category would lead to a $54.16 \%$ increase of visit frequency.

When region-specific coefficients for the four focal predictors are computed, the clear and simple picture disappears. Except for travel time, there are large differences between the study regions. For travel distance and for in-practice waiting time there are even statistically significant effects in opposite directions. This implies that there are statistically significant effects that are inconsistent with previous results and with intuition for each of the two variables. For travel distance, this holds for the English region, where this variable has a positive effect on visit frequency and, for in-practice waiting time, this holds for the Spanish region, where this variable has a positive effect (see Table 5). The most probable reason for the effect in the English region is that, in this region, travel distance is correlated with a further variable that has a positive impact on visit frequency and that is not contained in the regression model. For the Spanish region there seems to be something analogue for in-practice waiting time. The point is that the results suggest that travel distance and in-practice waiting time affect visit frequencies differently in different contexts. Although there is also an interaction effect for quality of communication, there is an essential commonality between all six study regions: visit frequencies always increase with quality of communication. In nine of 12 cases, this relationship is even statistically significant (see Table 5). Hence, there is a high probability that effects of this kind will also be found in regions that have not been investigated in this study.

Future development of health care provision might benefit from understanding reasons why most of the focal predictors have different relationships to visit frequencies in the different regions. One reason might be that the impact of the focal predictors is moderated by the country-specific regulations regarding access to health care providers. This hypothesis was tested by grouping the regions according to their country-specific regulations as described by the classification system of Reibling and by repeating the computations with this grouping. With this computation, the interaction effects strongly decrease, if they remain at all. This suggests that country-specific regulations regarding access to health care are not an important reason for different effects of the focal predictors in the different study regions. There must be different characteristics of the study region and/ or the study samples that are responsible for the interaction effects and identifying these would be a worthwhile subject for further research.

As the increase of visit frequency with quality of communication is the only stable effect, the question rises as to whether this relationship is causal with quality of communication as cause and visit frequency as the effect. As people generally tend to seek out other people with whom they have good communication, so it might be reasonable to interpret the relationship found here in this way. At least, this might be enough to justify the recommendation to increase quality of communication if there is an aim to increase the frequency of visits to the diabetes care provider.

\section{Conclusions}

Travel time, when controlled for travel distance, appears to have no impact on the frequency of visits to the diabetes care provider. For travel distance and in-practice waiting time, the effects are slight and inconsistent across study regions. In contrast, quality of communication has a strong positive effect on visit frequency. The strength of this relationship varies across study regions, but such a relationship was apparent in all of them, at least at a 
descriptive level. Therefore, if one seeks to increase the frequency of visits to the diabetes care provider increasing the quality of the provider's communication with the patient would be highly recommended.

\section{Abbreviations}

CW-Index: Index proposed by Cameron and Windmeijer for testing the fit of log-linear Poisson regression models; RCT: Randomised controlled trial

\section{Acknowledgements}

The surveys have been performed with the special assistance of Teresa Meneu and Antero Vanhala. Sibylle Robens gave some useful hints regarding the computation of the log-linear Poisson regression models. The authors would like to express their gratitude to the participating healthcare service provider organizations for their co-operation and support in enabling the study to take place.

These provider organizations were:

England: Dr. Gill Hood, North-East London Diabetes Research Network together with the Wapping Group Practice, the Spitalfields Practice, the Brayford Square Surgery, the Jubilee Street Practice, the Whitechapel Health Centre, the Tredegar Practice and the Chrisp Street Health Centre; Finland: the health centers of the municipalities of Joutsa, Keuruu, Konnevesi, Laukaa, Luhanka, Multia, Petäjävesi, and Toivakka;

Germany: the practice of Dr. Hans Martini, Dr. Günter Kraus and Herbert Högen in Memmelsdorf represented by Dr. Günter Kraus, the practice of Dr. Hubert Metzner in Bamberg, the practice of Dr. Axel Schleß in Bamberg, the practice of Drs. Gerhard and Dorothea Thiel in Lisberg-Trabelsdorf represented by Dr. Dorothea Thiel, and the practice of Dr. Christian Weghorn in Pommersfelden represented by Dr. Richard Barabasch;

Greece: the Diabetes Centre of the General Hospital of Herakleion, the local healthcare unit of the Health Insurance Fund, the Health Centre of Charakas and the municipal health center of Heraklion;

The Netherlands: the Healthcare Centre Tanthof in Delft, the Healthcare Centre De 1e Lijn in Den Hoorn, the Healthcare Centre Harris in Vlaardingen, the Healthcare Centre Nandoe en Schoute in 's Gravenzande, and the General Practitioner de Blooy in Hoek van Holland;

Spain: the Primary Care Centre Tendetes, which is one of the primary health areas belonging to the Valencia-La Fe Health Department.

\section{Authors' contributions}

UK has mainly developed the questionnaire, supervised the survey in all countries, performed the survey in Germany, analysed the data and wrote the main part of the manuscript. TM has essentially contributed to obtaining the funding, to organising the overall project, to the discussions during the development of the questionnaire and to performing the survey in Finland. $T B, S G E, R F, P F, E K, E P$ and PT have contributed to the discussions during the development of the questionnaire and have performed the surveys in their countries. All authors have read and approved the final draft of the manuscript.

\section{Funding}

The research leading to the results published in this article has received funding from the European Community's Seventh Framework Programme (FP7/2007-2013) under grant agreement number 241741. The funding organisation did not in any way influence the scientific work at this manuscript.

\section{Availability of data and materials}

The datasets used and/or analysed during the current study are available from the corresponding author on reasonable request.

\section{Ethics approval and consent to participate}

The English diabetes survey was approved by the NHS National Research Ethics Service (Skipton House, 80 London Road, London SE1 6LH). The Finnish survey was approved by the Ethics Committee of the Central Finland Health Care District. The German survey was approved by the Ethics Committee of the Medical Faculty of the Friedrich-Alexander University in Erlangen-Nürnberg. The Greek survey was approved by the Scientific Committee of the hospital in Heraklion and the Greek stroke survey by the Ethics Committee of the hospital Alexandra. The Dutch survey was approved by the board of directors of the Primary Care Group ZEL. The Spanish survey was approved by the Hospital La Fe Ethical Committee.

Participants gave their consent to participate by voluntarily handing over or voluntarily sending by mail the completed questionnaire. Survey participants were completely anonymous to the study researchers.

\section{Consent for publication}

Not applicable as no personal information is provided in the manuscript.

\section{Competing interests}

The authors declare that they have no competing interests.

\section{Author details}

${ }^{1}$ Trimberg Research Academy, University of Bamberg, 96045 Bamberg, Germany. ${ }^{2}$ Department of Psychology and Psychotherapy, Witten/Herdecke University, Alfred-Herrhausen-Straße 50, 58448 Witten, Germany. ${ }^{3}$ The Balance of Care Group, Camden Cottage, Bennett's Lane, Bath BA1 5JX, UK. ${ }^{4}$ Institute of Health Policy \& Management, Erasmus University Rotterdam, PO Box 1738, 3000 Rotterdam, DR, The Netherlands. ${ }^{5}$ Department of Physiotherapy, University of Valencia, Valencia, Spain. ${ }^{6}$ Joint Research Unit in Biomedical Engineering (IIS La Fe- Universitat Politècnica de València), Valencia, Spain. ${ }^{7}$ Department of Health Economics, National School of Public Health, 196 Alexandras Ave, 11521 Athens, Greece. ${ }^{8}$ Department of Industrial Engineering and Management, Aalto University, Espoo, Finland, PO Box 15500, 00076 Aalto, Finland. ${ }^{9}$ Present address: Department of Public Health, Faculty of Medicine, University of Helsinki, P.O. BOX 00020, 00014 Helsingin yliopisto, Finland.

Received: 8 March 2019 Accepted: 10 June 2020

Published online: 26 August 2020

\section{References}

1. Saeedi P, Petersohn I, Salpea P, Malanda B, Karuranga S, Unwin N, Colagiuri S, Guariguata L, Motala AA, Ogurtsova K, Shaw JE, Bright D, Williams RIDF. Diabetes Atlas Committee. Global and regional diabetes prevalence estimates for 2019 and projections for 2030 and 2045: Results from the International Diabetes Federation Diabetes Atlas, 9th edition. Diabetes Res Clin Pract. 2019;157:107843 https://doi.org/10.1016/j.diabres.2019.107843. Epub 2019 Sep 10

2. Nemet GF, Bailey AJ. Distance and health care utilization among the rural elderly. Soc Sci Med. 2000;50(9):1197-208.

3. Paul P, Heng BH, Seow E, Molina J, Tay SY. Predictors of frequent attenders of emergency department at an acute general hospital in Singapore. Emerg Med J. 2010;27(11):843-8 https://doi.org/10.1136/emj.2009.079160. Epub 2010 May 14.

4. Keasberry J, Munyombwe T, Duggal M, Day PF. A study of factors that influence the number of visits following traumatic dental injuries. Br Dent J. 2013;214(11):E28 https://doi.org/10.1038/sj.bdj.2013.532.

5. Cullinan J, Gillespie P, Owens L. Dunne FP; ALANTIC DIP collaborators. The impact of travel distance on the decision to attend for screening for gestational diabetes mellitus. Ir Med J. 2012;105(5 Suppl):18-20.

6. Kreher NE, Hickner JM, Ruffin MT 4th, Lin CS. Effect of distance and travel time on rural women's compliance with screening mammography: an UPRNet study. Upper peninsula research network. J Fam Pract. 1995;40(2): 143-7.

7. Konerding U, Bowen T, Elkhuizen SG, Faubel R, Forte P, Karampli E, Mahdavi M, Malmström T, Pavi E, Torkki P. The impact of travel distance, travel time and waiting time on health-related quality of life of diabetes patients: an investigation in six European countries. Diabetes Res Clin Pract. 2017;126: 16-24 https://doi.org/10.1016/j.diabres.2017.01.014

8. Andrade LF, Rapp T, Sevilla-Dedieu C. Exploring the determinants of endocrinologist visits by patients with diabetes. Eur J Health Econ. 2016; 17(9):1173-84 Epub 2016 Apr 2.

9. Li YN, Nong DX, Wei B, Feng QM, Luo HY. The impact of predisposing, enabling, and need factors in utilization of health services among rural residents in Guangxi, China. BMC Health Serv Res. 2016;16(1):592.

10. Masters SH, Burstein R, Amofah G, Abaogye P, Kumar S, Hanlon M. Travel time to maternity care and its effect on utilization in rural Ghana: a multilevel analysis. Soc Sci Med. 2013;93:147-54 https://doi.org/10.1016/j. socscimed.2013.06.012 Epub 2013 Jun 20. 
11. McDonald TP, Coburn AF. Predictors of prenatal care utilization. Soc Sci Med. 1988;27(2):167-72.

12. Littenberg B, Strauss K, MacLean CD, Troy AR. The use of insulin declines as patients live farther from their source of care: results of a survey of adults with type 2 diabetes. BMC Public Health. 2006;6:198.

13. Strauss K, MacLean C, Troy A, Littenberg B. Driving distance as a barrier to glycemic control in diabetes. J Gen Intern Med. 2006;21(4):378-80.

14. Zgibor JC, Gieraltowski LB, Talbott EO, Fabio A, Sharma RK, Hassan K. The association between driving distance and glycemic control in rural areas. J Diabetes Sci Technol. 2011;5(3):494-500.

15. Hafner P, Mahlich JC. Determinants of physician's office visits and potential effects of co-payments: evidence from Austria. Int I Health Plann Manag. 2016;31(3):e192-203 https://doi.org/10.1002/hpm.2316. Epub 2015 Sep 11.

16. Stentzel U, Bahr J, Fredrich D, Piegsa J, Hoffmann W, van den Berg N. Is there an association between spatial accessibility of outpatient care and utilization? Analysis of gynecological and general care. BMC Health Serv Res. 2018;18(1):322 https://doi.org/10.1186/s12913-018-3143-5.

17. Dixit A, Lee MC, Goettsch B, Afrane Y, Githeko AK, Yan G. Discovering the cost of care: consumer, provider, and retailer surveys shed light on the determinants of malaria health-seeking behaviours. Malar J. 2016;15:179 https://doi.org/10.1186/s12936-016-1232-7.

18. Tak HJ, Hougham GW, Ruhnke A, Ruhnke GW. The effect of in-office waiting time on physician visit frequency among working-age adults. Soc Sci Med. 2014;118:43-51 https://doi.org/10.1016/.socscimed.2014.07.053. Epub 2014 Jul 27.

19. Bundesmann R, Kaplowitz SA. Provider communication and patient participation in diabetes self-care. Patient Educ Couns. 2011;85(2):143-7 https://doi.org/10.1016/.pec.2010.09.025

20. Heisler M, Bouknight RR, Hayward RA, Smith DM, Kerr EA. The relative importance of physician communication, participatory decision making, and patient understanding in diabetes self-management. J Gen Intern Med. 2002;17(4):243-52.

21. Polonsky WH, Capehorn M, Belton A, Down S, Alzaid A, Gamerman V, Nagel F, Lee J, Edelman S. Physician-patient communication at diagnosis of type 2 diabetes and its links to patient outcomes: new results from the global IntroDia study. Diabetes Res Clin Pract. 2017;127:265-74 https://doi.org/10. 1016/.jiabres.2017.03.016. Epub 2017 Mar 22.

22. Managed Outcomes Consortium. Managed Outcomes. 2012. http://www. youtube.com/feed/UCGR1TTIICKmp-FHKH6cEAcg. Accessed 16 Jan 2020.

23. Malmström T, Auvinen A-M, Torkki P, Vanhala A, Peltokorpi A, Sievänen N, Konerding U, Vissers J. Managed outcomes, Deliverable 4: report on inventory and analysis of European practises in selected countries. Work report; 2012.

24. Reibling N. Healthcare systems in Europe: towards an incorporation of patient access. J Eur Soc Policy. 2010;20(1):5-18 https://doi.org/10.1177/ 0958928709352406.

25. Fishbein M, Aizen I. Belief, attitude, intention, and behavior: an introduction to theory and research. Reading: Addison-Wesley; 1975.

26. Greene WH. Econometric analysis. 3rd ed. Upper Saddle River: Prentice-Hall International, Inc.; 1997.

27. Dupre ME. Educational differences in age-related patterns of disease: reconsidering the cumulative disadvantage and age-as-leveler hypotheses. $J$ Health Soc Behav. 2007;48(1):1-15.

28. Dupre ME. Educational differences in health risks and illness over the life course: a test of cumulative disadvantage theory. Soc Sci Res. 2008;37(4): 1253-66.

29. Khang YH, Lynch JW, Kaplan GA. Health inequalities in Korea: age- and sexspecific educational differences in the 10 leading causes of death. Int J Epidemiol. 2004:33(2):299-308.

30. Silventoinen K, Lahelma E. Health inequalities by education and age in four Nordic countries, 1986 and 1994. J Epidemiol Community Health. 2002;56(4): 253-8.

31. Cameron A, Windmeijer F. R-Squared measures for count data regression models with applications to health care utilization. Working Paper No. 9324. Davis: Department of Economics, University of California; 1993.

\section{Publisher's Note}

Springer Nature remains neutral with regard to jurisdictional claims in published maps and institutional affiliations.

\section{Ready to submit your research? Choose BMC and benefit from:}

- fast, convenient online submission

- thorough peer review by experienced researchers in your field

- rapid publication on acceptance

- support for research data, including large and complex data types

- gold Open Access which fosters wider collaboration and increased citations

- maximum visibility for your research: over $100 \mathrm{M}$ website views per year

At BMC, research is always in progress.

Learn more biomedcentral.com/submissions 